\title{
Tectonic and manmade changes in hydrological system
}

\section{Opinion}

Neotectonic activities and changes in Landuse have shown its direct impact on surface water flow and groundwater quality. Indian rivers are showing variation in flood frequency and aggradational/degradational feature ${ }^{1}$ Geological variability and tectonic activities has the potential to change the groundwater quantity as well as quality. It is essential to monitor the hydrological system with precision ${ }^{2}$ Multispectral, Hyperspectral and Microwave sensors have proven techniques to infer the structural features and geomorphological changes in a tectonically active area. ${ }^{3}$ Case studies across the world shows the lineaments inferred in geospatial images has bearing with the movement of polluted water from ocean, estuary and rivers in different parts of the world e.g., Mersey Riverside UK, Medjerda basin of Tunisia, North Africa and West Coast of India. Neotectonic activities not only influence the landform and Land use but it has the potential to influence the water resources. Archival LANDSAT/IRS and latest CARTOSAT data of a part of the National Capital region shows that the Yamuna River has shifted towards north eastern direction in reference to the Delhi ridge. In the adjacent of Yamuna River, Gautam Buddha Nagar deposition of recent sand deposit proves that the river is shifting towards north eastern direction. Besides changes in the position of the river the sand-clay deposition has changed the groundwater quality. An investigation being carried out since last two decades in and around parts of Haryana-Delhi-Noida-Ghaziabad area to infer the changes in geological fracture/faults. These structural anomalies inferred as lineament length and density and its correlation with ground water quality are alarming for the local inhabitants of National Capital Region of India Surface water and Groundwater resources are dependent on each other. Terrain information is essential for the water resource understanding Surface water flows depends on the structural tectonics and geological variability Dissolution of the cations and anions varies in space and time depending on the tectonic and climate variations. In tectonically active areas if the rainfall is high the process of groundwater quality can be slow. Besides this microtremor activity within the semi arid area in a part of the National Capital Region has been studied to infer probable changes in the hydrogeochemistry of the alluvial aquifers. Epicentral clusters identified within Rohtak and Sonipat boundary as well as in the western Jhhajhar district which is North West of Delhi show water level fluctuations using the mean water level fluctuation from 2000 to 2016. The region with the water level rise and fall coincide with the area of the epicentral clusters. Further, it has been reported that the local topography of the area predisposes it to flooding events falling in the linear transect of Rohatak-Sirsa-Hissar as the region forms a saucer shaped depression causing the flood water to accumulate although no concrete evidence suggests so. The current study suggests that the region has frequent seismic activity along the intersection of the two regional faults causing abrupt water level fluctuations at these clusters. The hydrogeochemistry of the region shows that the groundwater has high salinity in some shallow and deeper aquifers probably due to the observed frequent water level fluctuations which
Volume I Issue I - 2017

\author{
Saumitra Mukherjee \\ School of Environmental Sciences, Jawaharlal Nehru University, \\ India
}

Correspondence: Saumitra Mukherjee, School of Environmental Sciences, Jawaharlal Nehru University, New Delhi-I I0067, India, Email saumitramukherjee3@gmail.com

Received: June 25, 2017 | Published: July 14, 2017

could be due to the combined effect of both anthropogenic factors (agricultural return flow, canal irrigation etc.) and natural factors (seismicity, high mineral dissolution etc.) or both. The water of the alluvial region of the study area where most of the seismic clusters are present has its major ion geochemistry mainly influenced from rock water interaction. Efflorescence evaporation due to irrigation return flow is also one of the main factors for the high salinity as well as the presence of some ionic concentrations in the aquifer samples besides silicate and carbonate weathering and mineral dissolution. Majority of the samples from the study region for pre-monsoon show both carbonate and silicate weathering as the processes controlling major ion chemistry whereas for post monsoon samples, majority shows increase in silicate weathering. Therefore, both ion exchange and reverse ion exchange processes are governing the chemistry of the aquifer waters in the pre-monsoon samples whereas the post-monsoon water chemistry is predominantly controlled by reverse ion exchange processes for a majority of the aquifer. The potential seismic hazard in Delhi and adjoining areas is attributed to the Himalayan Thrust System and reactivation of fault systems of the Delhi Fold Belt. The historical and modern seismicity records indicate that the fault Delhi-Sargodha Ridge (DSR) and Aravalli-Delhi Fold axis are the most seismically active zones. The seismicity of the region is due to bending of the lithosphere prior to underthrusting below the Himalayas. A study evaluating the seismic potentiality of Delhi-Rohtak area has also shown high percentage of $\mathrm{Fe}$ and $\mathrm{Mn}$ in active fault zones. ${ }^{4}$

\section{Acknowledgement}

None

\section{Conflict of interest}

The author declares no conflict of interest.

\section{References}

1. Kamal V, Mukherjee S, Singh P, et al. Flood frequency analysis of Ganga River at Haridwar and Garhmukteshwar. Applied Water Science. 2016;7(4):1979-1986.

2. Mukherjee S. Sensible measures to guard India's groundwater supply. Nature. 2009;462(7271):276. 
3. Mukherjee S. Role of Satellite Sensors in Groundwater Exploration Sensors. 2008;8(3):2006-2016.
4. Mukherjee S, Shashtri S, Singh CK, et.al. Effect of Canal on Land Use/Land Cover using Remote Sensing and GIS. Journal of the Indian Society of Remote Sensing. 2009;37(3):527-537. 